\title{
Histamine Receptor 1 and 2 Antagonists Alter Biodistribution of Radioiodine
}

\author{
Oliver Edwards ${ }^{1}$, Ellen D. Yakish, CNMT ${ }^{2}$, Li-Ming Wang ${ }^{1}$, Qi Wu ${ }^{1}$, John M. Hoffman ${ }^{1}$, and Kathryn A. Morton ${ }^{1}$ \\ ${ }^{1}$ Department of Radiology, University of Utah, Salt Lake City, Utah; and ${ }^{2}$ Intermountain Heart Center, Murray, Utah
}

\begin{abstract}
Nuclear medicine technology assumes responsibility for examinationspecific patient preparation procedures. This requires a clear understanding of the possible effects of medications on the outcome of examinations. There is evidence that common over-the-counter drugs, histamine $1(\mathrm{H} 1)$ and histamine $2(\mathrm{H} 2)$ receptor blockers and proton pump inhibitors, may directly or indirectly affect thyroid function. The objective was to determine whether short-term use of these drugs alters biodistribution of radioiodine in a rat model. Methods: Rats received no drug (controls) or daily subcutaneous injections of $\mathrm{H} 1$ blocker (promethazine), $\mathrm{H} 2$ blocker (famotidine), or proton pump inhibitor (esomeprazole) commencing $1 \mathrm{~d}$ before a single intraperitoneal injection of $0.037 \mathrm{MBq}(1 \mu \mathrm{Ci})$ of ${ }^{131} \mathrm{I}$ (Nal) and continuing daily until euthanasia at either $1 \mathrm{~d}$ or $8 \mathrm{~d}$ after ${ }^{131} \mathrm{I}$. Organ uptake of ${ }^{131} \mathrm{I}$ by control and drug-treated rats was compared by $y$-well counting. Results: Promethazine significantly increased uptake of ${ }^{131} \mathrm{I}$ by the thyroid (drug-treated-to-control ratios) both at $1 \mathrm{~d}(1.32)$ and $8 \mathrm{~d}(1.52)$ after ${ }^{131} \mathrm{I}$. Both famotidine and promethazine (respectively) significantly increased salivary gland uptake of ${ }^{131} \mathrm{I}$ (drug-treated-to-control ratios) at $1 \mathrm{~d}$ (1.37, 1.40) and $8 \mathrm{~d}(4.52,5.57)$ after ${ }^{131} \mathrm{I}$. Promethazine significantly increased gastric ${ }^{131} \mathrm{I}$ uptake (drug-treated-to-control ratios) at $1 \mathrm{~d}(1.47)$ and $8 \mathrm{~d}(1.46)$ after ${ }^{131} \mathrm{I}$. Famotidine and promethazine (respectively) significantly decreased uptake of ${ }^{131} \mathrm{I}$ by the liver (drug-treated-to-control ratios) at $1 \mathrm{~d}(0.60,0.71)$ after ${ }^{131}{ }^{13}$ but resulted in a marked increase over control levels $(11.21,9.28)$ at $8 \mathrm{~d}$. Blood levels of ${ }^{131} \mathrm{I}$ were not altered by drug treatment. Esomeprazole did not affect radioiodine distribution. Conclusion: $\mathrm{H} 1$ and $\mathrm{H} 2$ blockers alter the biodistribution of radioiodine in the rat. Although the findings remain to be confirmed in humans, these drugs could increase radiation exposure to nontarget tissues, particularly the stomach and salivary tissue, during ${ }^{131}$ I therapy and consideration should be given toward avoiding the elective use of these drugs during radioiodine therapy.
\end{abstract}

Key Words: rat; radioiodine; ${ }^{131}$;; biodistribution; drugs; sialadenitis; xerostomia; gastritis

J Nucl Med Technol 2015; 43:214-219

DOI: 10.2967/jnmt.115.160697

$\mathbf{T}$ he use of radioiodine for the treatment of hyperthyroidism and thyroid cancer remains efficacious since its initial

Received May 11, 2015; revision accepted Jun. 2, 2015.

For correspondence or reprints contact: Kathryn A. Morton, University of Utah,

Department of Radiology, 1A71, 50 N. Medical Dr., Salt Lake City, UT 84132.

E-mail: Kathryn.morton@hsc.utah.edu

Published online Jun. 25, 2015.

COPYRIGHT (C 2015 by the Society of Nuclear Medicine and Molecular Imaging, Inc. inception in the early 1940s. Since that time, the number of prescription and over-the-counter medications has rapidly increased. A wide variety of drugs has been proposed to alter the biodistribution of radioiodine, and these drugs are still being defined (1). Pharmaceutical-induced alterations in the biodistribution of radioiodine could not only affect the uptake of diagnostic or therapeutic radioiodine by the target thyroid tissue but also contribute to increased radiation exposure of nontarget organs and tissues. A clear understanding of the nature and effect of medications on the biodistribution of radioiodine is critical to the responsible practice of nuclear medicine technology and the provision of appropriate patient preparation instructions.

Commonly used over-the-counter medications that may affect thyroid function in complex ways include histamine 1 (H1) and histamine 2 (H2) receptor antagonists (blockers) as well as proton pump inhibitors (PPIs). H2 antagonists and PPIs are often recommended for control of dyspepsia in patients being treated with radioiodine (2). H1 antagonists may occasionally be used to treat pruritus (itching) and urticaria (hives) that may occur in patients with autoimmune hyperthyroidism. There is some evidence in the literature that histamine may affect the neuroendocrine-thyroid axis by complex mechanisms. Histamine has been shown to act on both the hypothalamus and the pituitary to inhibit thyroidreleasing hormone and thyroid-stimulating hormone $(3,4)$. Histamine receptor levels in the brain may be sensitive to thyroid function in both the developing and the adult brain (5). H2 receptors may mediate thyroid-releasing hormoneinduced increases in thyroxine excretion and may regulate hepatic metabolism of thyroid hormone (6). Conversely, H2 blockers can decrease secretion of thyroid-stimulating hormone possibly through a pituitary effect (7). H1-dependent secretion of thyroxine and triiodothyronine has also been described (8). PPIs have also been reported to affect thyroidstimulating hormone levels (9). H2 blockers and PPIs increase gastric retention of ${ }^{99 \mathrm{~m}} \mathrm{Tc}-\mathrm{O}_{4}$, which shares a similar biodistribution with radioiodine. However, there is controversy in the literature regarding the effect of $\mathrm{H} 2$ blockers or PPIs on gastric uptake of radioiodine $(10,11)$. Considering the frequency by which these drugs are used in the general population, the potential impact of these medications on the biodistribution of radioiodine by the thyroid, and the consequences of nontarget irradiation, a controlled study in rats was designed to determine whether short-term use of $\mathrm{H} 1$ 
and $\mathrm{H} 2$ antagonists as well as PPIs alters the biodistribution of radioiodine.

\section{MATERIALS AND METHODS}

\section{Study Design and Rationale}

To determine whether $\mathrm{H} 1$ or $\mathrm{H} 2$ blockers or PPIs alter the uptake of radioiodine by the thyroid and several normal tissues/organs, male Sprague-Dawley rats received no drug (controls) or daily subcutaneous injections of a prototypic $\mathrm{H} 1$ blocker (promethazine), $\mathrm{H} 2$ blocker (famotidine), or PPI (esomeprazole) commencing $1 \mathrm{~d}$ before the intraperitoneal injection of ${ }^{131} \mathrm{I}$ and continuing to the day of euthanasia ( 1 or $8 \mathrm{~d}$ after ${ }^{131}$ I injection). Uptake of ${ }^{131} \mathrm{I}$ by the thyroid, salivary gland tissue, stomach, liver, and whole blood was assayed by $\gamma$-well counting and compared between the control and drug-treated rats.

\section{Experimental Animals and Regulatory Assurance}

Adult male 2-mo-old Sprague-Dawley rats weighing 225-250 g (Harlan Laboratories) were used for the study. All procedures were performed according to a protocol approved by the Institutional Animal Care and Use Committee of the University of Utah (protocol no. 13-08011).

\section{Drug Administration}

The rats were divided into cohorts of 8 rats each. Each rat received a single intraperitoneal administration of $0.037 \mathrm{MBq}(1 \mu \mathrm{Ci})$ of ${ }^{131} \mathrm{I}(\mathrm{NaI})$ (in $100 \mu \mathrm{L}$ of isotonic saline). Rat cohorts received either no additional drug (controls) or daily subcutaneous injections of specific drug (famotidine, promethazine, or esomeprazole) commencing $1 \mathrm{~d}$ before ${ }^{131} \mathrm{I}(\mathrm{NaI})$ administration and continuing daily thereafter, until the day of euthanasia ( 1 or $8 \mathrm{~d}$ after radioiodine administration). The drug treatment protocol was as follows: H2 blocker, famotidine (3 mg/kg twice daily); H1 blocker, promethazine ( $1 \mathrm{mg} / \mathrm{kg}$ once daily); or PPI, esomeprazole $(5 \mathrm{mg} / \mathrm{kg}$ once daily).

\section{Tissue Determination of Radioiodine Levels}

After euthanasia, en bloc resection of the thyroid with adjacent adherent tissues was performed. Samples of (empty) stomach, submandibular salivary glands, liver, and whole blood were obtained and weighed. Tissue uptake of ${ }^{131} \mathrm{I}$ was then determined by $\gamma$-well counting. The tissue content of radioiodine was expressed as percentage injected dose per gram of tissue $(\% \mathrm{ID} / \mathrm{g})$ for all tissues except the thyroid. Thyroid uptake was expressed as \% ID for the entire thyroid gland. Radioiodine uptake was adjusted for nuclear decay.

\section{Statistical Analysis}

Biodistribution data were compiled as the mean \pm SE. Differences in organ uptake of ${ }^{131} \mathrm{I}$ by control and drug-treated rats were compared by 1-way ANOVA with Dunnett error protection (statistical significance defined as $P<0.05$ ).

\section{RESULTS}

\section{Thyroid}

Normal (control) uptake of ${ }^{131}$ I by the thyroid was lower for rats than for humans. The mean percentage uptake of radioiodine for the thyroid at $1 \mathrm{~d}$ after ${ }^{131} \mathrm{I}$ administration was $3.19 \%$, compared with typical values in the range of $8 \%-35 \%$ for healthy humans. Compared with control levels, radioiodine uptake by the thyroid was slightly but significantly increased in rats treated with the $\mathrm{H} 1$ blocker promethazine at $1 \mathrm{~d}$ (1.32-fold increase, $P=0.006)$ and $8 \mathrm{~d}$ (1.52-fold increase, $P=$ 0.008 ) after the administration of ${ }^{131} \mathrm{I}$ (Fig. 1). Compared with control rats, those treated with either famotidine $(\mathrm{H} 2$ blocker) or esomeprazole (PPI) showed no significant difference in radioiodine uptake by the thyroid at either 1 or $8 \mathrm{~d}$ after ${ }^{131} \mathrm{I}$ administration.

\section{Salivary Gland}

As shown in Figure 2, there was a slight but significant increase in uptake of radioiodine by salivary gland tissue $1 \mathrm{~d}$ after ${ }^{131} \mathrm{I}$ administration for both famotidine (1.37-fold increase, $P=0.006$ ) and promethazine (1.40-fold increase, $P=0.004)$, compared with control levels. However, there was a marked increase in salivary gland uptake of ${ }^{131} \mathrm{I}$ at $8 \mathrm{~d}$ in rats treated with famotidine (4.52-fold increase, $P<0.0001)$ and promethazine (5.57-fold increase, $P<0.0001$ ). Treatment with esomeprazole did not alter uptake of radioiodine by the salivary tissue at either 1 or $8 \mathrm{~d}$ after ${ }^{131} \mathrm{I}$ administration.

\section{Stomach}

Compared with control levels, radioiodine uptake by the stomach was significantly increased by the daily administration of promethazine both at $1 \mathrm{~d}$ (1.47-fold increase, $P=$ $0.035))$ and $8 \mathrm{~d}(2.46$-fold increase, $P<0.0001)$ after the

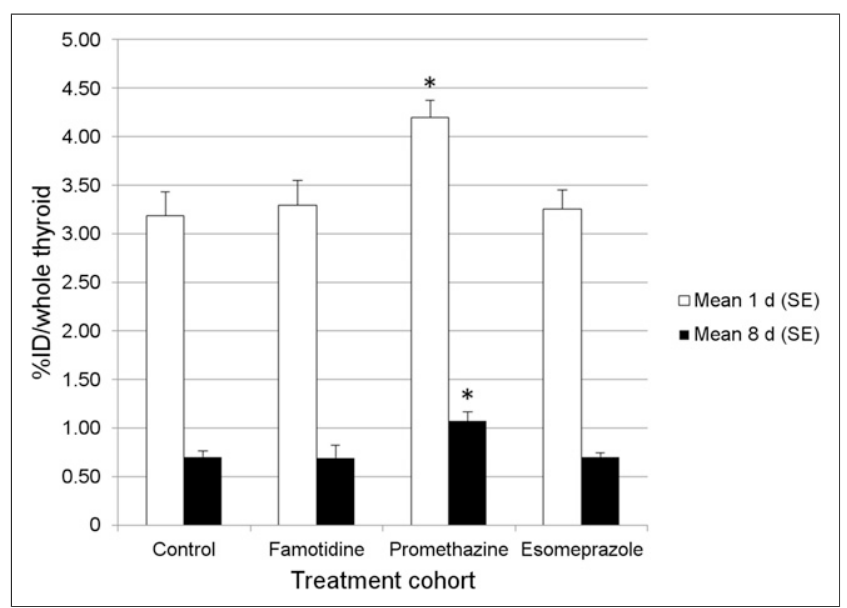

FIGURE 1. Effect of drug treatment on ${ }^{131}$ I uptake by thyroid. Shown are effects of treatment with $\mathrm{H} 1$ receptor antagonist (promethazine), $\mathrm{H} 2$ receptor antagonist (famotidine), and PPI (esomeprazole) on uptake of ${ }^{131}$ I (Nal) by entire thyroid (resected en bloc) in rat at $1 \mathrm{~d}$ (white bars) and $8 \mathrm{~d}$ (black bars) after intraperitoneal administration of radioiodine. Rat cohorts received either no additional drug (controls) or subcutaneous injections of specific drug (famotidine, promethazine, or esomeprazole) commencing $1 \mathrm{~d}$ before ${ }^{131} \mathrm{I}(\mathrm{Nal})$ administration and continuing daily thereafter until day of euthanasia (1 or $8 \mathrm{~d}$ after radioiodine administration). White and black bars denote mean uptake value (\%ID per entire thyroid) of radioiodine per cohort $(n=8$ for each cohort). Error bars represent SEM. Compared with untreated control rats, statistically significant increases in radioiodine uptake by thyroid occurred at both 1 and $8 \mathrm{~d}$ after ${ }^{131} \mathrm{I}$ administration only in promethazine-treated rats. Treatment with esomeprazole and famotidine did not alter radioiodine uptake by salivary tissue. *Statistically significant differences between drug-treated and control rats. 


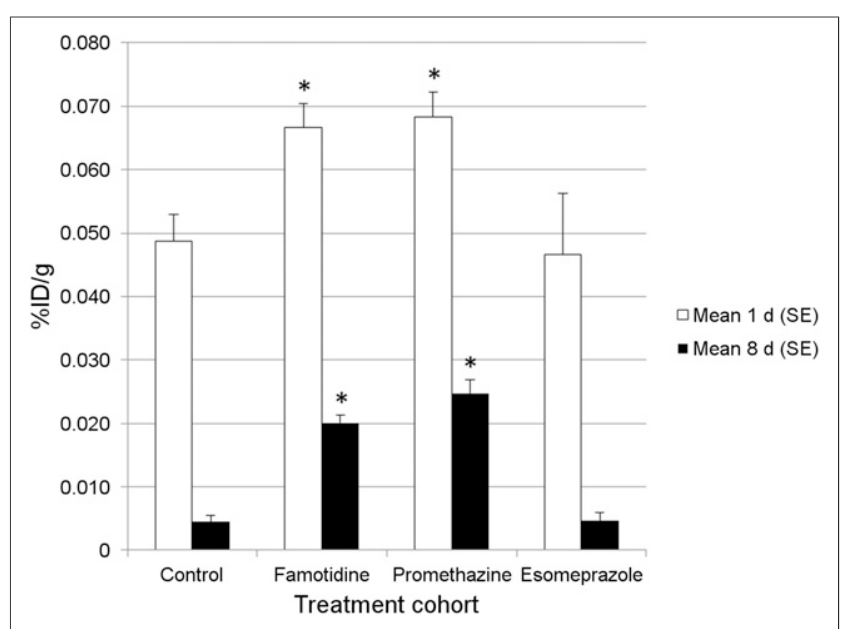

FIGURE 2. Effect of drug treatment on ${ }^{131}$ I uptake by salivary tissue. Shown are effects of $\mathrm{H} 1$ receptor antagonist (promethazine), $\mathrm{H} 2$ receptor antagonist (famotidine), and PPI (esomeprazole) on uptake of ${ }^{131} \mathrm{I}$ (Nal) by salivary gland tissue in rat at $1 \mathrm{~d}$ (white bars) and $8 \mathrm{~d}$ (black bars) after intraperitoneal administration of radioiodine. Rat cohorts received either no additional drug (controls) or subcutaneous injections of specific drug (famotidine, promethazine, or esomeprazole) commencing $1 \mathrm{~d}$ before ${ }^{131} \mathrm{I}$ (Nal) administration and continuing daily thereafter until day of euthanasia (1 or $8 \mathrm{~d}$ after radioiodine administration). White and black bars denote mean uptake value $(\% \mathrm{ID} / \mathrm{g})$ of radioiodine per cohort $(n=8$ for each cohort). Error bars represent SEM. Compared with untreated control rats, statistically significant increases in radioiodine uptake by salivary gland tissue occurred at both 1 and $8 \mathrm{~d}$ after ${ }^{131} \mathrm{I}$ administration in both famotidine- and promethazine-treated rats. Esomeprazole did not affect salivary gland uptake of radioiodine. *Statistically significant differences between drug-treated and control rats.

administration of ${ }^{131} \mathrm{I}$ (Fig. 3). Compared with control rats, those treated with either famotidine or esomeprazole showed no significant difference in radioiodine uptake by the stomach at either 1 or $8 \mathrm{~d}$ after ${ }^{131} \mathrm{I}$ administration.

\section{Liver}

As shown in Figure 4, when compared with control levels, there was a slight but significant decrease in liver uptake of ${ }^{131} \mathrm{I}$ at $1 \mathrm{~d}$ in both famotidine- (1.67-fold decrease, $P=0.005)$ and promethazine- (1.41-fold decrease, $P=$ 0.016) treated rats. However, compared with control levels, there was a marked increase in uptake of ${ }^{131}$ I uptake by the liver $8 \mathrm{~d}$ after ${ }^{131} \mathrm{I}$ administration in rats treated with daily famotidine (11.21-fold increase, $P=0.019)$ and promethazine $(9.28$-fold increase, $P<0.0001)$. There was no significant difference in uptake of radioiodine by the liver between control rats and those treated with esomeprazole at either 1 or $8 \mathrm{~d}$ after ${ }^{131} \mathrm{I}$ administration.

\section{Whole Blood}

Whole-blood levels of ${ }^{131} \mathrm{I}$ decreased markedly from 1 to $8 \mathrm{~d}$ after radioiodine administration. There were no significant differences in content of radioiodine in the blood in control rats at either 1 or $8 \mathrm{~d}$ after ${ }^{131} \mathrm{I}$ administration, compared with those treated with famotidine, promethazine, or esomeprazole (Fig. 5).

\section{DISCUSSION}

The organs and tissues selected for analysis in this project were chosen for specific reasons. Selected organs/tissues include the thyroid itself and organs that typically receive a relatively high absorbed dose of radiation during ${ }^{131}$ I treatment for hyperthyroidism or thyroid cancer, including the salivary tissue and stomach. Whole blood, which is an indicator of whole-body burden of radioiodine and an indirect indicator of bone marrow exposure, was also assayed. Radioiodine uptake by the liver was also measured because of data that support that hepatic metabolism of thyroid hormone may be regulated by $\mathrm{H} 2$ receptors (6). Although the bladder wall also receives a relatively high dose of exposure (from urinary excretion), urine activity was not assayed because of the volatile nature of ${ }^{131} \mathrm{I}$ in the urine and difficulty with an accurate collection in small rodents. Whether the drugs tested could affect urinary excretion of ${ }^{131}$ I was not tested but is thought to be unlikely given the lack of variability in blood levels of radioiodine between the control rats and the drug-treated cohorts.

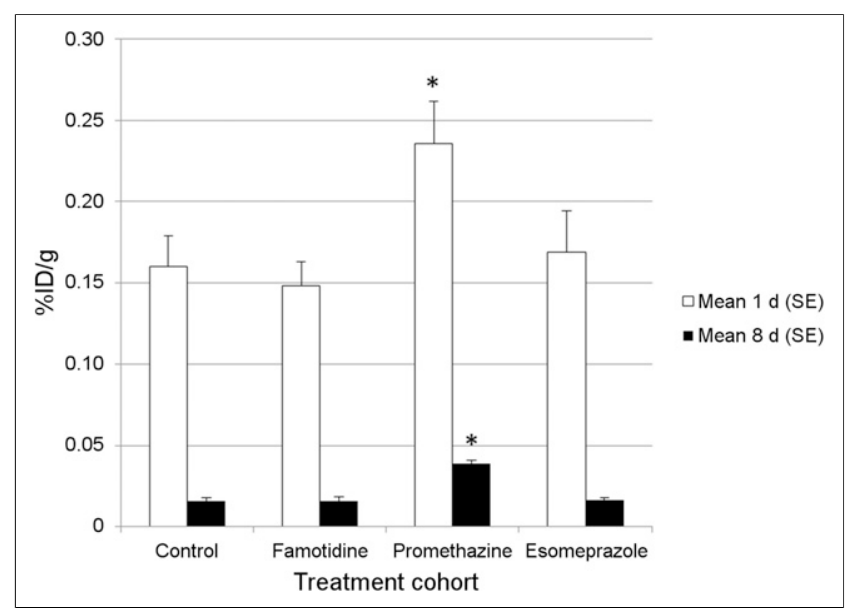

FIGURE 3. Effect of drug treatment on ${ }^{131}$ I uptake by stomach. Shown are effects of treatment with $\mathrm{H} 1$ receptor antagonist (promethazine), $\mathrm{H} 2$ receptor antagonist (famotidine), and PPI (esomeprazole) on uptake of ${ }^{131}$ I (Nal) by (empty) stomach in rat at $1 \mathrm{~d}$ (white bars) and $8 \mathrm{~d}$ (black bars) after intraperitoneal administration of radioiodine. Rat cohorts received either no additional drug (controls) or subcutaneous injections of specific drug (famotidine, promethazine, or esomeprazole) commencing $1 \mathrm{~d}$ before ${ }^{131} \mathrm{I}$ (Nal) administration and continuing daily thereafter until day of euthanasia ( 1 or $8 \mathrm{~d}$ after radioiodine administration). White and black bars denote mean uptake value $(\% \mathrm{ID} / \mathrm{g})$ of radioiodine per cohort $(n=8$ for each cohort). Error bars represent SEM. Compared with untreated control rats, statistically significant increases in radioiodine uptake by stomach occurred at both 1 and $8 \mathrm{~d}$ after 131। administration only in promethazine-treated rats. Treatment with esomeprazole and famotidine did not alter gastric radioiodine uptake. *Statistically significant differences between drug-treated and control rats. 


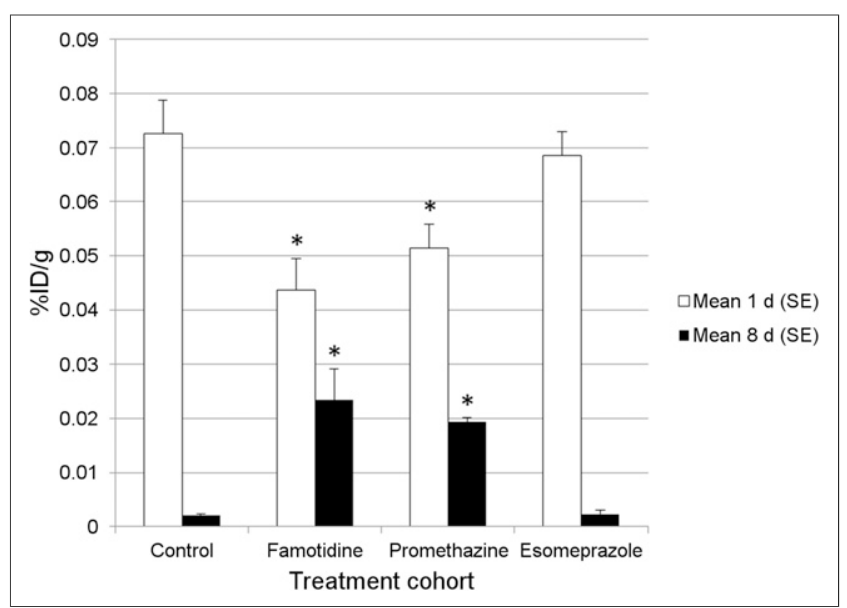

FIGURE 4. Effect of drug treatment on ${ }^{131}$ I uptake by liver. Shown are effects of treatment with $\mathrm{H} 1$ receptor antagonist (promethazine), $\mathrm{H} 2$ receptor antagonist (famotidine), and PPI (esomeprazole) on uptake of ${ }^{131}$ I (Nal) by liver in rat at $1 \mathrm{~d}$ (white bars) and $8 \mathrm{~d}$ (black bars) after intraperitoneal administration of radioiodine. Rat cohorts received either no additional drug (controls) or subcutaneous injections of specific drug (famotidine, promethazine, or esomeprazole) commencing $1 \mathrm{~d}$ before ${ }^{131}$ I $(\mathrm{Nal})$ administration and continuing daily thereafter until day of euthanasia (1 or $8 \mathrm{~d}$ after radioiodine administration). White and black bars denote mean uptake value $(\% / D / g)$ of radioiodine per cohort ( $n=8$ for each cohort). Error bars represent SEM. Compared with untreated control rats, statistically significant decreases in radioiodine uptake by liver occurred at $1 \mathrm{~d}$ after ${ }^{131} \mathrm{I}$ administration in both famotidine- and promethazine-treated rats. At $8 \mathrm{~d}$ after ${ }^{131} \mathrm{I}$ administration, opposite pattern occurred, with significant increase in hepatic uptake of ${ }^{131} \mathrm{I}$ in famotidine- and promethazine-treated rats, compared with controls. Esomeprazole did not alter hepatic radioiodine uptake. *Statistically significant differences between drug-treated and control rats.

Compared with controls, treatment with the $\mathrm{H} 1$ receptor blocker promethazine resulted in an increase in radioiodine uptake by the thyroid, both at $1 \mathrm{~d}$ after ${ }^{131} \mathrm{I}$ administration (1.3-fold increase) and at $8 \mathrm{~d}$ after ${ }^{131} \mathrm{I}$ administration (1.5-fold increase). This result suggests that the use of H1 blockers could confound the results of diagnostic tests of radioiodine uptake and uptake determinations that are made for the purpose of calculating an appropriate dose for treatment of hyperthyroidism. If the radioactive iodine uptake and therapeutic administration of ${ }^{131} \mathrm{I}$ are done under different conditions of exposure to $\mathrm{H} 1$ blockers, then dosimetric decisions based on the radioactive iodine uptake determinations could be inaccurate. There is no information provided by this study to indicate that any of the drugs tested result in alterations in uptake of ${ }^{131} \mathrm{I}$ by well-differentiated thyroid cancer. Famotidine (H2 blocker) and esomeprazole (PPI) do not affect radioiodine uptake by the thyroid at either 1 or $8 \mathrm{~d}$ after ${ }^{131} \mathrm{I}$ administration.

Sialadenitis and a dry mouth (xerostomia) caused by radiation damage to salivary tissue is one of the more common and bothersome side effects of ${ }^{131} \mathrm{I}$ therapy. There are also some data that support an increase in secondary primary salivary gland malignancies in thyroid cancer patients treated both with low (ablative) and high doses of ${ }^{131} \mathrm{I}(12,13)$. Measures to mitigate radiation damage to the salivary tissue are typically aggressively used with ${ }^{131} \mathrm{I}$ treatment, including the use of salivation-inducing maneuvers, such as sucking on sour candy, chewing gum, and good oral hydration. Despite these maneuvers, there is significant variability in the magnitude of uptake of radioiodine observed in the salivary tissue on clinical radioiodine scans, either with ${ }^{123} \mathrm{I}$, or on posttherapy ${ }^{131} \mathrm{I}$ scans after treatment of thyroid cancer. The causes of variability in magnitude of uptake of radioiodine by salivary tissue are not well understood. However, concomitant use of either $\mathrm{H} 1$ or $\mathrm{H} 2$ blockers, which are commonly taken as overthe-counter drugs, could contribute to higher levels of uptake of ${ }^{131} \mathrm{I}$ in some patients. With $\mathrm{H} 1$ and $\mathrm{H} 2$ blocker treatment, there is a 1.37- and 1.40-fold increase, respectively, over control levels in radioiodine uptake by the salivary gland $1 \mathrm{~d}$ after administration of ${ }^{131}$ I. Treatment with $\mathrm{H} 1$ and $\mathrm{H} 2$ blockers results in more substantial elevations in uptake of radioiodine by salivary tissue $8 \mathrm{~d}$ after ${ }^{131} \mathrm{I}$ administration (4.5- and 5.57-fold increase over control levels), suggesting that both increased uptake and delayed clearance of radioiodine by salivary tissue may

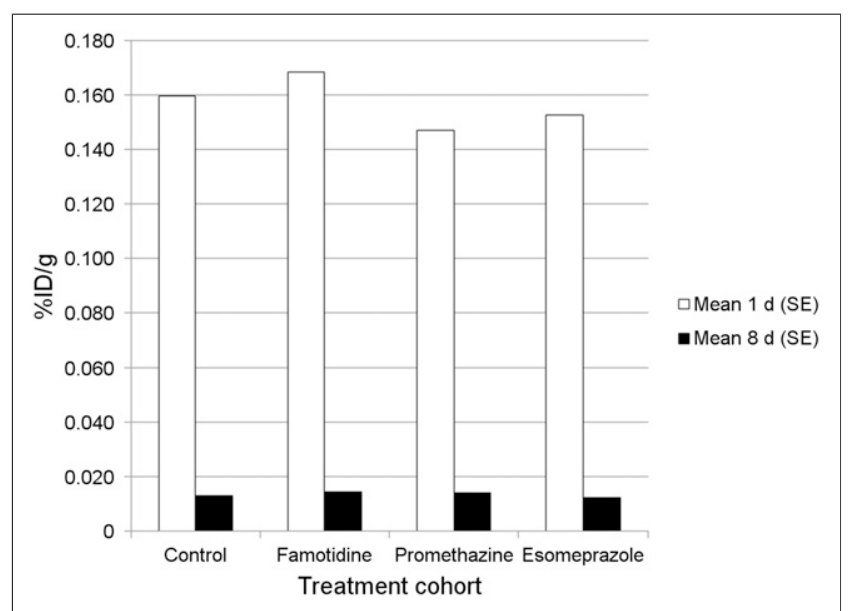

FIGURE 5. Effect of drug treatment on ${ }^{131}$ I uptake by whole blood. Shown are effects of treatment with $\mathrm{H} 1$ receptor antagonist (promethazine), $\mathrm{H} 2$ receptor antagonist (famotidine), and PPI (esomeprazole) on uptake of ${ }^{131}$ I (Nal) by whole blood in rat at $1 \mathrm{~d}$ (white bars) and $8 \mathrm{~d}$ (black bars) after intraperitoneal administration of radioiodine. Rat cohorts received either no additional drug (controls) or subcutaneous injections of specific drug (famotidine, promethazine, or esomeprazole) commencing $1 \mathrm{~d}$ before ${ }^{131} \mathrm{I}$ (Nal) administration and continuing daily thereafter until day of euthanasia ( 1 or $8 \mathrm{~d}$ after radioiodine administration). White and black bars denote mean uptake value $(\% \mathrm{ID} / \mathrm{g})$ of radioiodine per cohort ( $n=8$ for each cohort). Error bars represent SEM. When compared with control rats, no significant differences were noted in content of ${ }^{131} \mid$ in whole-blood samples for rats treated with any of the 3 drugs either at 1 or at $8 d$ after radioiodine administration. 
result from nonspecific histamine receptor blockade. That $\mathrm{H} 1$ and $\mathrm{H} 2$ blockers could contribute to the complication of sialadenitis, dry mouth, and salivary gland malignancies with radioactive iodine treatment is a theoretic risk but one that is relatively easily prevented, by avoidance of these drugs in patients who will receive ${ }^{131}$ I for therapeutic purposes.

Compared with control levels, radioiodine uptake by the stomach was significantly increased by promethazine treatment both at $1 \mathrm{~d}$ (1.47-fold increase) and at $8 \mathrm{~d}$ (2.46-fold increase) after the administration of ${ }^{131} \mathrm{I}$. The gastric wall receives a relatively high absorbed dose of radiation with ${ }^{131}$ I treatment, which has raised theoretic concerns for radiation-induced gastritis and late atrophic gastritis as complications of radioiodine treatment. A recent report cites an increased risk of second primary tumors, including those of the stomach, in thyroid cancer survivors, although it is not clear whether this is due to radioiodine treatment (14). A possible trend in induction of gastric cancers from radioactive iodine associated with treatment of benign thyroid diseases has also been reported, although this remains to be conclusively confirmed (15). It is therefore possible that irradiation of the gastric wall from ${ }^{131}$ I may increase the risk of gastric cancer. Treatment of rats with famotidine or esomeprazole did not result in any change in gastric uptake of radioiodine.

The liver may be an important organ in the microsomal deiodination of T4 to T3 and in the modulation of systemic effects of thyroid hormone (16). There is also evidence that histamine may play a role in the regulation of hepatic metabolism of thyroid hormone (6). There is a slight but significant decrease in radioiodine uptake by the liver at $1 \mathrm{~d}$ after ${ }^{131} \mathrm{I}$ administration in both famotidine- (1.67-fold decrease) and promethazine- (1.41-fold decrease) treated rats. However, compared with control levels, there is a marked increase in uptake of ${ }^{131} \mathrm{I}$ by the liver $8 \mathrm{~d}$ after ${ }^{131} \mathrm{I}$ administration in rats treated with daily famotidine (11.21-fold increase) and promethazine (9.28-fold increase). The basis for these observations is unclear but supports an active role in the processing of thyroid hormone by the liver, which can be significantly altered by both $\mathrm{H} 1$ and $\mathrm{H} 2$ blockers. There is no significant difference in uptake of radioiodine by the liver between control rats and those treated with esomeprazole at either 1 or $8 \mathrm{~d}$ after ${ }^{131} \mathrm{I}$ administration.

There are some limitations with regard to this study. To ensure that all rats received an equivalent amount of radioiodine systemically, ${ }^{131}$ I was administered by intraperitoneal injection. This route of administration should reproduce the vascular drainage pathway resulting from oral administration of radioiodine (mesenteric veins to portal vein). The intraperitoneal route of administration has been used in several rodent studies examining the biodistribution and therapeutic effects of radioiodine (17-19). Although there is no theoretic mechanistic basis to suggest that $\mathrm{H} 1$ or $\mathrm{H} 2$ blockers or PPIs could alter enteric absorption of ${ }^{131} \mathrm{I}$, this was not specifically assessed and the future confirmation of the effects of these medications with an oral route of radioiodine administration may be appropriate. In addition, further studies to confirm that effects in humans similar to those we have demonstrated in this preclinical rodent model are observed may also be warranted.

Despite these limitations, there is sufficient preclinical experimental evidence provided herein to support that elective use of $\mathrm{H} 1$ blockers be discontinued before diagnostic measurements of radioiodine uptake by the thyroid. Both $\mathrm{H} 1$ and $\mathrm{H} 2$ blockers should be withheld before, and at least $1 \mathrm{wk}$ after, ${ }^{131} \mathrm{I}$ administration for therapeutic purposes. In this study, esomeprazole did not alter the biodistribution of radioiodine. However, there is a single brief report describing increased uptake of radioiodine by the stomach in patients taking omeprazole, another PPI, compared with patients not taking the drug (10). The interval necessary for discontinuation of the drugs before ${ }^{131} \mathrm{I}$ administration would vary as a function of the specific pharmacokinetic profile of the formulation, which can generally be obtained from the available drug package insert. In general, it is necessary to wait $\mathbf{4 - 5}$ elimination half-lives after cessation of a drug before pharmacologic activity is no longer present. However, it is important to realize that elimination half-lives can be altered by liver and kidney disease and are generally longer when a drug is taken chronically, rather than sporadically.

\section{CONCLUSION}

This preclinical study in a rat model supports that 2 categories of commonly used drugs, $\mathrm{H} 1$ and $\mathrm{H} 2$ receptor antagonists, alter the biodistribution of ${ }^{131} \mathrm{I}(\mathrm{NaI})$. Although comparison studies in humans have not been performed, the preclinical evidence herein supports that it may be appropriate to avoid the use of these drugs in patients in whom diagnostic or therapeutic administration of radioiodine is required.

\section{DISCLOSURE}

No potential conflict of interest relevant to this article was reported.

\section{REFERENCES}

1. Mettler FA. Essentials of Nuclear Medicine. 6th ed. Philadelphia, PA: Elsevier Saunders; 2012.

2. Strauss WM, Mariani G, Volterrani D, et al. Nuclear Oncology: Pathophysiology and Clinical Applications. New York, NY: Springer; 2012.

3. Mitsuma T, Nogimori T, Sun DH, et al. Effects of histamine and related compounds on thyrotropin secretion in rats. Horm Res. 1986;23:99-105.

4. Silva JD, Nunes MT. The role of histamine on the control of thyrotropin secretion in rats. Agents Actions Suppl. 1992;36:282-286.

5. Codolà R, García A. Effect of thyroid state on histamine H1 receptors in adult and developing rat brain. Biochem Pharmacol. 1985;34:4131-4136.

6. Perret G, Hugues JN, Louchahi M, et al. Effect of a short-term oral administration of cimetidine and ranitidine on the basal and thyrotropin-releasing hormone-stimulated serum concentrations of prolactin, thyrotropin and thyroid 
hormones in healthy volunteers: a double-blind cross-over study. Pharmacology. 1986;32:101-108.

7. Ulloa ER, Zaninovich AA. Effects of histamine H1- and H2-receptor antagonists on thyrotrophin secretion in the rat. J Endocrinol. 1986;111:175-180.

8. Danowski J, Kmieć BL. Histochemical and biochemical studies on the secretory mechanisms of some glands of guinea-pigs treated with histamine. Folia Histochem Cytobiol. 2002;40:213-214

9. Sachmechi I, Reich DM, Aninyei M, et al. Effect of proton pump inhibitors on serum thyroid-stimulating hormone level in euthyroid patients treated with levothyroxine for hypothyroidism. Endocr Pract. 2007;13:345-349.

10. Castro G, Berrocal I, Carmona J, et al. ${ }^{131}$ I gastric uptake with and without omeprazole in patients undergoing radioiodine therapy for differentiated thyroid carcinoma. Eur J Nucl Med Mol Imaging. 2012;39:13561357.

11. Sfakianakis G, Sfakianaki E. The sodium-iodine symporter and the proton-pump inhibitors in-related to the side effects of - the treatment of thyroid cancer with iodine-131. Hell J Nucl Med. 2007;10:2-5.

12. Iyer NG, Morris LG, Tuttle RM, et al. Rising incidence of second cancers in patients with low-risk (T1N0) thyroid cancer who receive radioactive iodine therapy. Cancer. 2011;117:4439-4446.
13. Rubino C, de Vathaire F, Dottorini ME, et al. Second primary malignancies in thyroid cancer patients. Br J Cancer. 2003;89:1638-1644.

14. Subramanian S, Goldstein DP, Parlea L, et al. Second primary malignancy risk in thyroid cancer survivors: a systematic review and meta-analysis. Thyroid. 2007;17: 1277-1288.

15. Hieu TT, Russell AW, Cuneo R, et al. Cancer risk after medical exposure to radioactive iodine in benign thyroid diseases: a meta-analysis. Endocr Relat Cancer. 2012;19:645-655.

16. Malik R, Hodgson $\mathrm{H}$. The relationship between the thyroid gland and the liver. QJM. 2002;95:559-569.

17. Hanauer G, Schroth HJ. Estimate of the dosage for radioiodine ablation of the thyroid gland in male Wistar rats. Zentralbl Veterinarmed A. 1990;37:747751.

18. Turgut B, Ozdemir O, Erselcan T. Evaluation of the p53 tumor suppressor gene mutation in normal rat salivary gland tissue after radioiodine application: an experimental study. Adv Ther. 2006;23:456468.

19. Matovic MD, Jankovic SM, Jeremic M, et al. Effect of furosemide on radioiodine-131 retention in mice thyroid gland. Hell J Nucl Med. 2009;12: $129-131$. 